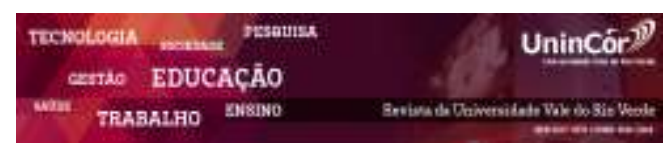

Revista da Universidade Vale do Rio Verde ISSN: 1517-0276 / EISSN: 2236-5362 Vol. 16 | n. 1 | Ano 2018

Paulo Roberto Tamandaré Lopes Universidade de Rio Verde paulorobertotamandare@gmail.com

Lenny Francis Campos de Alvarenga Universidade de Rio Verde continental.op@bol.com.br

Lainny Oliveira Dias Universidade de Rio Verde lainnydias@gmai.com

Kátia Cristina Fontana Universidade de Rio Verde katiafontana.kf@outlook.com

Nathalia Townsend Carvalho de Oliveira Universidade de Rio Verde nathaliatownsend@gmail.com

Claudio Herbert Nina e Silva Universidade de Rio Verde claudioherbert@unirv.edu.br

\section{TERAPIA DE BIOCAMPO TOQUE QUÂNTICO NÃO TEM EFEITO SOBRE O CRESCIMENTO DE PLÂNTULAS DE SOJA (Glycine max)}

\section{RESUMO}

O objetivo do presente estudo foi investigar o efeito do toque quântico sobre o crescimento de plântulas de soja (Glycine max). Em partes iguais, uma amostra de 80 sementes de soja foi distribuída em dois grupos: Experimental (com tratamento de toque quântico durante 20 minutos antes do plantio) e Controle (sem tratamento antes do plantio). Em desacordo com a literatura, os resultados indicaram que não houve diferenças entre as taxas de germinação e o comprimento médio das plântulas dos dois grupos. Concluiu-se que o toque quântico não teve efeito fisiológico sobre o crescimento de plântulas de soja.

Palavras-chave: Terapias Integrativas e Complementares. Experiências anômalas. Imposição de Mãos. Biocampo.

\section{QUANTUM TOUCH BIOFIELD THERAPY HAS NO EFFECT ON SOYBEAN (Glycine max) SEEDLINGS GROWTH}

\begin{abstract}
The objective of this study was to investigate the effect of the quantum touch on the growth of soybean seedlings (Glycine max). In equal parts, a sample of 80 soybean seeds was divided into two groups: Experimental (treatment with quantum touch for 20 minutes before planting) and Control (no treatment before planting). In disagreement with the literature, the results showed no differences between the germination rates and the average length of seedlings of both groups. It was concluded that the quantum touch had no physiological effect on the growth of soybean seedlings.
\end{abstract}

Keywords: Epidemic clinic profile. Childhood traumatism. Pediatric Intensive Care. Respiration, artificial Traumatism.

Recebido em: 04/11/2016 - Aprovado em: 10/01/2018 - Disponibilizado em: 15/07/2018

\section{INTRODUÇÃO}

O toque quântico é uma terapia de biocampo que afirma trabalhar com um tipo de energia denominada força vital presente em todos os organismos (GORDON, 2001).

Em várias partes do mundo em diferentes culturas e religiões, ao longo de milhares de anos, 
notam-se várias designações para a força vital (BRENNAN, 1987; GERBER, 1988; GORDON, 2001).

Na China ela é conhecida como $C h i$, no Japão de Ki. Essa energia é utilizada em diversos métodos de curas, que envolvem massagens, acupuntura e artes maciais. Para os Kuhuna, no Havaí, a força vital chama-se Mana, utilizada como cura pelas mãos à distância em suas orações. Na Índia a utilização da força vital ocorre de forma surpreendente, os iogues chamam a energia de Prana, e a utilizam para alcançar os mais elevados estados de consciência por meio da yoga, meditação, pranayama, e outras formas de curas (BRENNAN, 1987; GERBER, 1988; GORDON, 2001).

O praticante do toque quântico se utiliza de pensamento para criar intenções e vários tipos de vibrações para, assim, gerar um campo de alta energia, envolvendo a área que necessita de cura para esse campo. (GORDON, 2001).

Um dos elementos que compõe o método do toque quântico é a ressonância. A área a ser curada tende a seguir a vibração do terapeuta, levantando-se e mantendo-se elevada. Dessa forma entende-se que ninguém pode curar ninguém, pois o terapeuta apenas mantém uma ressonância que permite ao organismo atendido se curar (GORDON, 2001).

O toque quântico é um tipo de terapia de biocampo que se enquadra na categoria de terapia de imposição de mãos. Por sua vez, as terapias de imposição de mãos têm sido consideradas práticas integrativas e complementares (WILKINSON et al., 2012; GRONOWICZ et al., 2015).
Atendendo à recomendação da Organização Mundial da Saúde, o Ministério da Saúde brasileiro formulou e tem buscado implementar a Política Nacional de Práticas Integrativas e Complementares (PNPIC) direcionada para o uso judicioso das práticas integrativas e complementares no Sistema Único de Saúde (BRASIL, 2006).

Além disso, o PNPIC prevê a necessidade do desenvolvimento de pesquisa científica sobre a eficácia das práticas integrativas e complementares (BRASIL, 2006).

Vários estudos têm demonstrado a eficácia clínica das terapias de biocampo de imposição de mãos (ABE et al., 2012; HAMMERSCHLAG et al., 2014; GRONOWICZ et al., 2015; RADIN et al., 2015). Apesar disso, ainda não foi possível avaliar a relação entre fatores psicológicos e a eficácia clínica das terapias de biocampo de imposição de mãos (ABE et al., 2012).

Para avaliar o efeito fisiológico das terapias de biocampo de imposição de mãos em contraposição aos fatores psicológicos, vários trabalhos têm estudado a influência da aplicação de técnicas de imposição de mãos em plantas como indicadores (GRAD, 1963; GRAD, 1964; RONEY-DOUGAL; SOLFVIN, 2002; BRAGA et al., 2003; RONEY-DOUGAL; SOLFVIN, 2003; NINA-E-SILVA et al., 2017; OLIVEIRA et al., 2017).

Dessa forma, o objetivo do presente estudo foi avaliar o efeito do toque quântico sobre o crescimento de plântulas de soja (Glycine max). 


\section{MÉTODOS}

Este estudo foi uma pesquisa experimental realizada no Laboratório de Psicologia Anomalística e Neurociências, Faculdade de Psicologia, Universidade de Rio Verde. Uma amostra de 80 sementes de soja foi separada ao acaso de um lote de 500 gramas de sementes fornecido pela Faculdade de Agronomia da Universidade de Rio Verde. A taxa de germinação média dessas sementes foi calculada pela Faculdade de Agronomia da Universidade de Rio Verde como sendo de $89 \%$, índice considerado ótimo para o plantio.

As sementes da amostra foram divididas igualmente em dois grupos: 1) Grupo Experimental, no qual as sementes de soja foram tratadas com a aplicação do toque quântico durante 20 minutos antes do plantio; e 2) Grupo Controle, no qual as sementes não foram tratadas com a aplicação de toque quântico antes do plantio.

Foram utilizados como vasos para o plantio das sementes, 16 baldes de plástico polipropileno de 4,5 litros, os quais foram colocados sobre duas bancadas de madeira, cada uma com extensão de $50 \mathrm{~cm}$ de largura e $70 \mathrm{~cm}$ de comprimento, de frente para janelas que permitiram livre exposição aos raios solares.

A terra colocada nos vasos foi retirada do mesmo local em que se fazem os experimentos da Faculdade de Agronomia da Universidade de Rio Verde, sendo peneirada para a sua melhor qualidade. Folhas de papel jornal foram colocadas no fundo dos vasos para retenção da água. Após o preenchimento com a terra, cada um dos vasos recebeu $500 \mathrm{ml}$ de água.

Cada grupo era composto por oito vasos, sendo que foram plantadas cinco sementes em cada vaso, com um espaçamento de $3,5 \mathrm{~cm}$ entre elas, constituindo um total de 40 sementes por cada grupo.

A profundidade de cada cova para plantio foi de $2 \mathrm{~cm}$. Depois do plantio das sementes de ambos os grupos, cada vaso recebeu $500 \mathrm{ml}$ de água por meio de um recipiente plástico graduado em mililitros para garantir a precisão na quantidade de água.

$\mathrm{O}$ experimento foi encerrado no $15^{\circ}$ dia após o plantio. As plântulas foram retiradas do solo e medidas com uma fita métrica para a realização da comparação de crescimento entre grupos. A medição se deu do comprimento das raízes até a extremidade dos caules (NAKAGAWA, 1994). No Grupo Experimental uma das sementes germinadas não se desenvolveu, não sendo somada a esta análise.

A temperatura ambiente foi mantida constante em $20^{\circ} \mathrm{C}$ durante todos os 16 dias de realização do experimento por meio de aparelho de ar condicionado. De acordo com Gianluppi et al. (2009), as condições ótimas de temperatura para a cultura da soja estão entre $20^{\circ} \mathrm{C}$ e $30^{\circ} \mathrm{C}$.

Os dados foram analisados pelo programa Statistica for Windows 10.0. O teste $t$ para duas amostras presumindo variâncias diferentes foi utilizado com nível de significância $p<0,05$. 


\section{RESULTADOS E DISCUSSÃO}

A Tabela 1 apresenta a quantidade total de sementes germinadas em cada dia no Grupo Experimental e no Grupo Controle. O dia 03 de setembro de 2015 foi o último dia em que houve a germinação de sementes. $O$ experimento encerrou-se com $90 \% \quad(n=36)$ das sementes germinadas no Grupo Experimental, e 92,5\% $(n=37)$ no Grupo Controle.

Tabela 1 - Quantidade total de sementes germinadas em cada dia de experimento em cada um dos grupos.

\begin{tabular}{ccc}
\hline Data & Grupo Experimental & Grupo Controle \\
\hline $27 / 08 / 2015$ & - & - \\
$28 / 08 / 2015$ & - & - \\
$29 / 08 / 2015$ & 01 & - \\
$30 / 08 / 2015$ & 04 & 03 \\
$31 / 08 / 2015$ & 18 & 27 \\
$01 / 09 / 2015$ & 34 & 35 \\
$02 / 09 / 2015$ & 35 & 37 \\
$03 / 09 / 2015$ & 36 & 37 \\
\hline
\end{tabular}

Fonte: Os autores.

Esses resultados estão de acordo com a previsão de percentual de taxa de germinação das sementes fornecida pela Faculdade de Agronomia da Universidade de Rio Verde.

Os dados indicaram que não houve diferença na taxa de germinação das sementes de soja entre os grupos, pois as sementes de ambos os grupos germinaram praticamente no mesmo período, e a taxa de sementes germinadas foi praticamente igual em ambos os grupos.

Não houve diferença significativa entre os comprimentos das plântulas dos grupos Experimental $(\mathrm{M}=26,11, \mathrm{DP}=10,40)$ e Controle $(\mathrm{M}=26,91, \mathrm{DP}=8,50) ; t_{(75)}=-0,38, p=0,0775$.

As folhas do Grupo Experimental variaram de $3,5 \mathrm{~cm}$ a $4,5 \mathrm{~cm}$ de largura. Já o comprimento das folhas variou de $4 \mathrm{~cm}$ a $7 \mathrm{~cm}$, e as raízes variaram de $6 \mathrm{~cm}$ a $9 \mathrm{~cm}$ de comprimento. As folhas do Grupo Controle variaram de $2 \mathrm{~cm}$ a $4,5 \mathrm{~cm}$ de largura. Já o comprimento variou de $3 \mathrm{~cm}$ a $7 \mathrm{~cm}$. As raízes variaram de $5 \mathrm{~cm}$ a $10 \mathrm{~cm}$ de comprimento. Não foram constatadas diferenças no tamanho das folhas e das raízes de ambos os grupos.

Esses resultados não estão de acordo com estudos prévios segundo os quais o tratamento de sementes com terapia de biocampo de imposição de mãos resultou em plântulas com comprimento médio significativamente maior do que plântulas oriundas de sementes não tratadas com técnica de imposição de mãos (GRAD, 1963; GRAD, 1964; RONEY-DOUGAL; SOLFVIN, 2002; BRAGA et al., 2003; RONEYDOUGAL; SOLFVIN, 2003; CREATH; SCHWARTZ, 2004; OLIVEIRA et al., 2017).

A discrepância entre os presentes resultados e achados prévios poderia ser explicada pela ineficácia da técnica de toque quântico, o tipo de espécie botânica ou o estado emocional do aplicador da técnica. A hipótese de ineficácia da técnica de toque quântico é a menos provável devido ao fato de vários outros trabalhos já terem demonstrado o efeito fisiológico positivo da técnica de imposição de mãos em seres humanos, animais e plantas 
(GRAD， 1963， 1964; KRIEGER, 1979; SCOFIELD; HODGES, 1991; HODGES; SCOFIELD, 1995; GORDON, 2001; BRAGA et al., 2003; CRAWFORD et al., 2003; PIERCE, 2007; SAVIETO et al., 2007; JAIN; MILLS, 2010; ABE et al., 2012; SCHILTZ et al., 2012; WILKINSON et al., 2012; HAMMERSCHLAG et al., 2014; GRONOWICZ et al., 2015; RADIN et al., 2015; ROE et al., 2015; OLIVEIRA et al., 2017).

A hipótese da influência da espécie botânica seria mais provável, embora requeira estudos adicionais para verificá-la, pois nenhum dos estudos anteriores que relataram efeito fisiológico positivo da terapia de biocampo de imposição de mãos foi realizado com soja (GRAD， 1963; GRAD, 1964; RONEYDOUGAL; SOLFVIN, 2002; BRAGA et al., 2003; RONEY-DOUGAL; SOLFVIN，2003; CREATH; SCHWARTZ, 2004).

A hipótese da influência do estado emocional do aplicador também é provável, visto que o toque quântico é uma técnica energética que acontece por meio da vibração de quem a produz, para que assim outro organismo possa receber essa vibração (GORDON, 2001). Dessa forma, a eficácia da técnica é suscetível aos estados emocionais de quem a está aplicando. Sugere-se, portanto, a realização de novos estudos experimentais que avaliem a influência do estado emocional do aplicador sobre a eficácia da terapia de biocampo toque quântico.

Após a retirada das plantas dos vasos para medição no dia 11 de setembro de 2015, uma semente germinou no Grupo Experimental. A plântula oriunda dessa semente sobreviveu até o dia 28 de outubro de 2015 sem água. Não se sabe ao certo os fatores que deram condições para a planta permanecer viva por mais de um mês sem água.

Acredita-se que a semente ter germinado após a retirada das plântulas pode ter sido devido ao fato de a semente ter melhores condições para germinar, pois antes disputava nutrientes com outras quatro plântulas em desenvolvimento. Além disso, a sobrevivência da planta sem água também pode ter sido decorrente de a plântula estar em um laboratório, não sendo exposta a condições naturais adversas e eventuais pragas. No entanto, por se tratar de uma plântula oriunda de uma semente do Grupo Experimental, o toque quântico poderia ser o responsável por essa resistência à seca. Todavia, essa hipótese requer a realização de um experimento para investigá-la.

\section{CONCLUSÃO}

Os presentes resultados indicaram que a terapia de biocampo toque quântico não teve efeito fisiológico sobre o crescimento das plântulas de soja.

\section{AGRADECIMENTOS}

Ao Prof. Me. Alberto Barella Neto (PróReitoria de Admnistração e Planejamento) pelo equipamento necessário à realização dos experimentos. À Pró-Reitoria de Pós-Graduação e Pesquisa da Universidade de Rio Verde pela bolsa de PIBIC concedida a Kátia Cristina Fontana e pela inclusão de Nathalia Townsend Carvalho de Oliveira no PIVIC/UniRV. 


\section{REFERÊNCIAS}

ABE, K. Effect of a Japanese energy healing method known as Johrei on viability and proliferation of cultured cancer cells in vitro. The Journal of Alternative and Complementary Medicine, v.18, n.3, p.221-228, 2012.

BRAGA, M.P. et al. Efeito da imposição das mãos (Johrei) sobre a viabilidade de grãos de pólens e produção de sementes de pepino em estufa.

Horticultura Brasileira, v. 21, n. 2, p.187-192, 2003.

BRASIL. Política Nacional de Práticas Integrativas e Complementares no SUS. Brasília: Ministério da Saúde, 2006.

BRENNAN, B. A. Mãos de luz: um guia para a cura através do campo de energia humana. São Paulo: Editora Pensamento, 1987.

CRAWFORD, C.C. et al. A systematic review of the quality of research on hands-on and distance healing: clinical and laboratory studies. Alternative Therapies in Health and Medicine, v.9, n.3, p.96-104, 2003.

CREATH, K.; SCHWARTZ, G.E. Measuring effects of music, noise, and healing energy using a seed germination bioassay. The Journal of Alternative and Complementary Medicine, v.10, n.1, p.113-121, 2004.

GERBER, R. Medicina vibracional: uma medicina para o futuro. São Paulo: Editora: Cultrix, 1988.

GIANLUPPI, V. et al. Cultivo de soja no cerrado de Roraima. Embrapa Roraima Sistemas de Produção. 2009. Disponível em:

<http://sistemasdeproducao.cnptia.embrapa.br/FontesH TML/Soja/CultivodeSojanoCerradodeRoraima/autores. htm>. Acesso em: 23 set 2015.

GORDON, R. Toque Quântico: o poder de curar. São Paulo: Editora Madras, 2001.

GRAD, B. A telekinetic effect on plant growth. International Journal of Parapsychology, v.5, p.117-133, 1963.

GRAD, B. A telekinetic effect on plant growth-II. International Journal of Parapsychology, v.6, p.473498, 1964.

GRONOWICZ, G. Challenges for preclinical investigation of human biofield modalities. Global Advances in Health and Medicine, v.4, p.52-57, 2015.

HAMMERSCHLAG, R. et al. Nontouch biofield therapy: a systematic review of human randomized controlled trials reporting use of only nonphysical contact treatment. The Journal of Alternative and Complementary Medicine, v.10, n.12, p.881-892, 2014.

HODGES, R.D.; SCOFIELD, A.M. Is spiritual healing a valid and effective therapy? Journal of the Royal Society of Medicine, v.88, p.203-207, 1995.

KRIEGER, D. The therapeutic touch. Englewood Cliffs: Prentice Hall, 1979.

NAKAGAWA, J. Testes de vigor baseados na avaliação das plântulas. In: VIEIRA, R. D.; CARVALHO, N. M. (Orgs.). Testes de vigor em sementes. Jaboticabal: FUNEP, 1994. p. 49- 86.

NINA-E-SILVA, C.H. et al. Índice de velocidade de emergência de sementes de feijão preto (Phaseolus vulgaris) tratadas com toque quântico. Salusvita, v.36, n.1, p.55-63, 2017.

OLIVEIRA, A.C.R. et al. Efeito fisiológico da Intenção de Cura à Distância sobre crescimento de feijão. In: Anais do III Congresso de Medicina e Saúde Coletiva do Sudoeste Goiano, p. 77-79, 2017.

PIERCE, B. The use of biofield therapies in cancer care. Clinical Journal of Oncology Nursing, v.11, n.2, p.253-258, 2007.

RADIN, D. et al. Distant healing intention: an overview of the scientific evidence. Global Advances in Health and Medicine, v.4, p.67-71, 2015.

ROE, C.A. et al. Two meta-analyses of noncontact healing studies. Explore, v.11, p.11-23, 2015.

RONEY-DOUGAL, S.M.; SOLFVIN, J. Field study of enhancement effect on lettuce seeds: their germination, growth and health. The Journal of the Society for Psychical Research, v.66, p.129-143, 2002.

RONEY-DOUGAL, S.M.; SOLFVIN, J. Field study of enhancement effect on lettuce seeds: replication study. Journal of Parapsychology, v.67, n.2, p.279298, 2003.

SAVIETO, R. M. et al. Ação da água energizada com o toque terapêutico na cicatrização de lesões na pele de camundongos. Revista Enfermagem UERJ, v.15, n.3, p.423-429, 2007.

SCHILTZ, M. et al. Distant healing of surgical wounds: an exploratory study. Explore (NY), v.8, n.4, p.223-230, 2012.

SCOFIELD, A.M.; HODGES, R.D. Demonstration of a healing effect in the laboratory using a simple plant 
